\title{
Sciatic neuropathy caused by an intermuscular lipoma in dogs
}

\author{
Piotr Trębacz, Marek Galanty \\ Warsaw University of Life Sciences (SGGW), Faculty of Veterinary Medicine, \\ Division of Small Animal Surgery, Warsaw, Poland \\ Received November 25, 2016 \\ Accepted June 1, 2016
}

\begin{abstract}
Lipomas are common, usually slow-growing, benign tumours of mesenchymal origin that most commonly occur on the proximal limb and trunk of middle-aged to older dogs. They are rarely associated with either local invasion or malignancy, unlike infiltrative lipomas and liposarcomas, respectively. Three dogs, a 10-year-old mixed-breed female of $35 \mathrm{~kg}$ body weight, a 10 -yearold mixed-breed male of $30 \mathrm{~kg}$ body weight, and an 11-year old female German shepherd of $38 \mathrm{~kg}$ body weight, were presented with a 3-6 month (median, 5 months) history of progressive left pelvic limb lameness and thigh swelling. A lesion affecting the soft tissue of the thigh and the left sciatic nerve was suspected in all dogs. A left thigh magnetic resonance (MR) revealed a homogenous, well circumscribed tumour in the mixed-breed dogs and two similar tumours in the German shepherd. The tumours were interposed between the semimembranosus and semitendinosus muscles. The treatment involved surgical extirpation of the tumours. A follow-up examination 12 months post operation showed mild lameness and proprioceptive deficits in the operated limb in all the dogs. The withdrawal reflex and the cranial tibial reflex were normal. Neither mass nor thickening were palpable in the thigh region. Although intermuscular lipoma is rare, it should be suspected in dogs with progressive monoparesis. Magnetic resonance is a valuable imaging method for diagnostic precision and pre-operative planning. Quick diagnosis and decompressive surgery are required to allow recovery.
\end{abstract}

Canine, benign tumour, sciatic nerve

The sciatic nerve is a major nerve contributing to the pelvic limb flexor reflex. Its damage results in severe monoparesis. The stifle does not flex and the hock and the digits do not flex or extend. Injury to the sciatic nerve in dogs can be associated with pelvic trauma, impingement from a femoral intramedullary pin, entrapment by a suture following perineal herniorrhaphy, intramuscular injections and with infiltrative neoplasia (Gemmill and McKee 2012).

Lipomas are common, usually slow-growing, benign tumours of mesenchymal origin that most commonly occur on the proximal limb and trunk of middle-aged to older dogs. They are rarely associated with either local invasion or malignancy, unlike infiltrative lipomas and liposarcomas, respectively (Bergman et al. 1994; Thomson et al. 1999; Szabo et al. 2011; Case et al. 2012). Majority of lipomas occur in the subcutaneous tissue, intermuscular, intramuscular and paraosteal localizations. Intraosseous lipomas are uncommon in dogs (Nacladal et al. 2012).

Intermuscular lipomas in dogs can be associated with ominous clinical signs. Generaly they occur in the caudal thigh, mostly between the semimembranosus and semitendinosus muscles (Thomson et al. 1999; Case et al. 2012).

This paper describes three cases of dogs with hindlimb lameness caused by the intermuscular lipomas compressing a sciatic nerve.

\section{Materials and Methods}

A 10-year-old female mixed-breed dog of $35 \mathrm{~kg}$ body weight (Case 1), a 10-year-old male mixed-breed dog of $30 \mathrm{~kg}$ body weight (Case 2), and an 11-year old female German shepherd dog of $38 \mathrm{~kg}$ body weight (Case 3)

Address for correspondence:

Dr Piotr Trebacz

Division of Small Animal Surgery

Faculty of Veterinary Medicine

Warsaw University of Life Sciences

Nowoursynowska 159 c, 02-776, Warsaw, Poland 
were presented with a 3-6 month (median, 5 months) history of progressive left pelvic limb lameness and thigh swelling. The tarsus was extended and the toes were knuckled. A lesion affecting the soft tissue of the thigh and the left sciatic nerve was suspected.

On examination the dogs showed generalized, firm and painless swelling of the left thigh (Plate X, Fig. 1). Neurologically, conscious propioceptive deficit was observed. Hyporeflexia of the withdrawal reflex and cranial tibial reflex were stated. Concurrent pseudo-hyperreflexia of the patellar reflex was also observed. Instead of neurological disturbances the dogs were clinically sound.

A left thigh magnetic resonance (MR) was done in all dogs.

\section{Results}

The MR revealed a homogenous, well circumscribed tumour in the mixed-breed dogs (Cases 1 and 2) and two similar tumours in the German shepherd (Case 3) (Plate X, Fig. 2). The tumours were interposed between the semimembranosus and semitendinosus muscles and demonstrated a hyperintense signal on T1-weighted images and a relatively high signal on T2-weighted images. The signal intensity was similar to that of subcutaneous fat. There were no muscular or bony involvements. The sciatic nerves were not visualized.

The treatment involved surgical extirpation of the tumours. With the dog in lateral recumbency, an incission was made along the caudal aspect of the thigh over the swelling. The semitendinosus and semimembranosus muscle bellies were separated using blunt dissection to expose the mass. The tumours were separated from the surrounding tissue using a combination of blunt dissection and digital extrusion. The sciatic nerve was identified and protected during dissection (Plate X, Fig. 3). The tumours were removed in their entirety (Plate X, Fig. 4), and were histopathologically proven to be the benign lipomas.

A follow-up examination 2 weeks and 2 months post operation showed fast improvement of the neurological status. A follow-up examination 12 months post operation showed mild lameness and proprioceptive deficits in the operated limb in all dogs. The withdrawal reflex and the cranial tibial reflex were normal. Neither mass nor thickening were palpable in the thigh region.

\section{Discussion}

Clinical signs secondary to the intermuscular lipoma compressing the peripheral nerves are rare in dogs. Szabo et al. (2011) described one dog with forelimb lameness. The dog had a tumour in the carpal canal, compressing the median and ulnar nerves. Case et al. (2012) described intermuscular lipomas in 17 dogs. One dog had an ipsilateral Horner's syndrome caused by a lipoma in the axillary region. The tumour compressed the sympathetic trunk. So far, we have not found any information about a case of sciatic nerve compression by an intermuscular lipoma in dogs. In a study of 11 intermuscular lipomas of the thigh region in dogs, tumours had to be carefully dissected from around the sciatic nerve in three cases (Thomson et al. 1999). However, the study does not comment on whether the nerve was compressed or whether the affected animals had clinical signs of sciatic nerve compression.

The sciatic nerve is a major nerve innervating the pelvic limbs. In injuries to its proximal part, the digits, hock, and stifle do not flex when the toes are stimulated. In the treated dogs we observed the loss of the withdrawal reflex and the cranial tibial reflex. Simultaneously, the strong patellar reflex was noted. The patellar reflex is not affected by the sciatic nerve so the muscle tone of the stifle extensors (femoral nerve) will override that of the flexors (sciatic nerve).

Animals suffering from progressive neurological deficits caused by compression of the neural structures should be managed surgically (Szabo et al. 2011; Case et al. 2012). Pre-operative diagnostics are intended to confirm the diagnosis, localise the lesion and 
Table 1. Comparison of described cases of intermuscular lipoma compressing peripheral nerves in dogs.

\begin{tabular}{|c|c|c|c|c|c|c|c|}
\hline Author & $\begin{array}{c}\text { Number } \\
\text { of treated dogs }\end{array}$ & $\begin{array}{l}\text { Age (years) } \\
\text { Sex }\end{array}$ & $\begin{array}{c}\text { Clinical } \\
\text { presentation }\end{array}$ & $\begin{array}{l}\text { Location } \\
\text { of lipoma }\end{array}$ & $\begin{array}{c}\text { Compressed } \\
\text { nerve }\end{array}$ & Treatment & Results \\
\hline $\begin{array}{l}\text { Szabo } \\
\text { et al. } \\
(2011)\end{array}$ & 1 & $50^{\lambda}$ & $\begin{array}{l}\text { forelimb } \\
\text { lameness }\end{array}$ & carpal canal & $\begin{array}{l}\text { median } \\
\text { and ulnar }\end{array}$ & extirpation & very good \\
\hline $\begin{array}{l}\text { Case } \\
\text { et al. } \\
(2012)\end{array}$ & 3 & not specified & $\begin{array}{c}\text { forelimb lameness } \\
\text { ipsilateral } \\
\text { Horner's syndrome } \\
\text { not specified } \\
\text { not specified }\end{array}$ & $\begin{array}{l}\text { antebrachium } \\
\text { axillary region } \\
\text { e not specified }\end{array}$ & $\begin{array}{c}\text { median } \\
\text { vago- } \\
\text { sympathetic trunk }\end{array}$ & extirpation & very good \\
\hline $\begin{array}{l}\text { Trębacz } \\
\text { described } \\
\text { cases }\end{array}$ & 3 & $\begin{array}{l}109 \\
119 \\
10 \hat{\gamma}\end{array}$ & $\begin{array}{l}\text { hindlimb } \\
\text { lameness }\end{array}$ & $\begin{array}{c}\text { between the } \\
\text { semimembranosus } \\
\text { and semitendinosus } \\
\text { muscles }\end{array}$ & sciatic & extirpation & good* \\
\hline
\end{tabular}

* - some prioprioceptive deficits in the affected limb

exclude other differential diagnoses. Clinical signs allow gross lesion location only. Magnetic resonance imaging provides much information on soft tissue pathology and on anatomic relations, and it is therefore preferable for diagnostic precision and pre-operative planning. In this study the sciatic nerves were not visualized because they were compressed by large tumours. Generally, visualisation of the peripheral nerves may be difficult in routine MR sequences (T1 and T2). The difficulty occurs due to the signal from fat and blood vessels surrounding the nerve of interest. Other factor includes the variable course of the nerve, as the nerve may travel in various planes throughout its course (Bagley et al. 2009).

Surgery is the treatment of choice for an intermuscular lipoma. After extirpation of tumours and decompression of the sciatic nerve, fast resolution of neurological symptoms was observed. Similar results were reached by Case et al. (2012) and Szabo et al. (2011).

In conclusion, although the intermuscular lipoma is rare, it should be suspected in dogs with progressive monoparesis. Magnetic resonance is a valuable imaging method for diagnostic precision and pre-operative planning. Quick diagnosis and decompressive surgery are required for recovery to follow.

\section{References}

Bagley RS, Gavin PR, Holmes SP 2009: Magnetic resonance imaging of peripheral nerve disease. In: Gavin PR and Bagley RS (Eds): Practical Small Animal MRI. Wiley-Blackwell, Ames, 228 p.

Bergman PJ, Withrow SJ, Straw RC, Powers BE 1994: Infiltrative lipomas in dogs: 16 cases (1981-1992). J Am Vet Med Assoc 205: 322-324

Case JB, McPhail CM, Withrow SJ 2012: Anatomic distribution and clinical findings of intermuscular lipomas in 17 dogs (2005-2010). J Am Anim Hosp Assoc 48: 245-249

Gemmill T, McKee M 2012: Monoparesis and neurological causes of lameness. In: Platt SR and Garosi LS (Eds): Small Animal Neurological Emergencies. Manson Publishing, London, 313 p.

Nakladal B, vom Hagen F, Olias P, Brunberg L 2012: Intraosseus lipoma in the ulna and radius of a two-year-old Leonberger. Vet Comp Orthop Traumatol 25: 144-148

Szabo D, Ryan T, Scott W 2011: Carpal canal lipoma causing lameness in a dog. Vet Comp Orthop Traumatol 24: 299-302

Thomson M, Withrow SJ, Dernell WS, Powers BE 1999: Intermuscular lipomas of the thigh region in dogs: 11 cases. J Am Anim Hosp Assoc 35: 165-167 
Plate X

Trębacz P. et al.: Sciatic neuropathy ... pp. 147-149

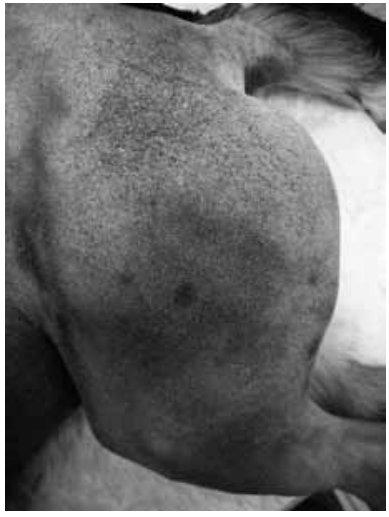

Fig. 1. Female German shepherd (Case 3). Generalized swelling of the left thigh is well visible.

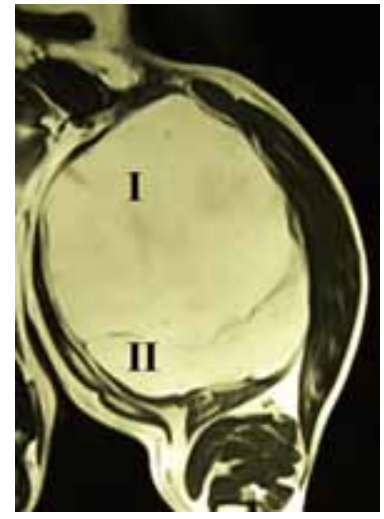

Fig. 2. Female German shepherd (Case 3). Transverse T1-weighted MR image of the left thigh. Two (I, II) homogenous well circumscribed tumours are visible. The tumours are separating the semimembranosus and semitendinosus muscle bellies. The tumours' signal intensity is similar to that of subcutaneous fat.

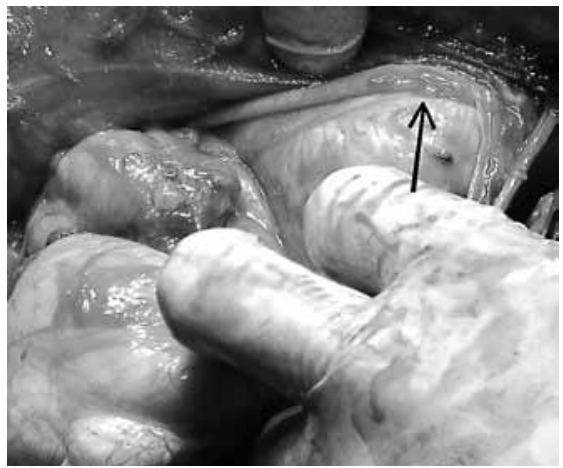

Fig. 3. Female German shepherd (Case 3) - intraoperative view. The sciatic nerve compressed by the tumour is visible (black arrow).

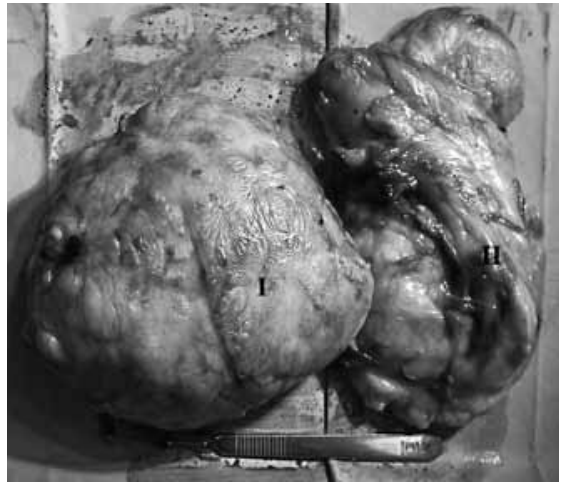

Fig. 4. Female German shepherd (Case 3). Two lipomas (I, II) removed in their entirety. 